EDITORIAL

\title{
Atrial fibrillation: will new drugs and patient choice improve anticoagulation outcomes?
}

\author{
R Fuller, N J Dudley
}

The growing epidemic of atrial fibrillation presents major challenges to the healthcare community, both clinical and financial

See end of article for authors' affiliations

Correspondence to:

Dr Richard Fuller, Medical Department for the Elderly, The General Infirmary at Leeds, Leeds LS1 3EX, UK; ftworf@aol.com
$\mathrm{T}$ he management of non-valvar atrial fibrillation (AF) presents a significant challenge to clinicians worldwide, with an estimated 2.5 million patients affected across the USA and UK alone. ${ }^{12}$ At least $15 \%$ of all ischaemic strokes may be attributable to underlying $\mathrm{AF}$ and an individual's annual risk of stroke may be as high as $18 \%$ depending on the number of risk factors, including age. ${ }^{34}$ With the number of stroke events expected to rise as the prevalence of $\mathrm{AF}$ and the aging population increases, this "epidemic" of AF has significant financial implications; a recent economic analysis suggested that almost $1 \%$ of National Health Service expenditure in 2000 arose because of AF and its related outcomes. ${ }^{2}$ Improving prevention of AF related strokes should be a health care priority from both an individual and a national point of view.

\section{ANTICOAGULANTS: RISKS, CONTROL, AND OUTCOMES}

Large scale trials have demonstrated the efficacy of both aspirin and warfarin in preventing thromboembolic stroke associated with $\mathrm{AF}$, with a respective $22 \%$ and $62 \%$ relative risk reduction in rates of stroke. ${ }^{5}$ Why then do so few patients receive warfarin despite its clear benefits? There is clear evidence that significant numbers of patients do not receive anticoagulation when it is appropriate and community surveys suggest that less than $25 \%$ of those who are eligible receive warfarin treatment. ${ }^{6}$ Decisions around anticoagulation are complex and heuristical with physicians striving to balance risks and benefits, often avoiding adverse bleeding related outcomes, but overlooking the unseen benefits of stroke prevention. For both physicians and patients, the annual risk of intracerebral bleeding of up to $2 \%$ is a major contributing factor in a decision to withhold or avoid warfarin. ${ }^{78}$

For those patients who do opt for warfarin, long term anticoagulation poses many problems-regular phlebotomy based monitoring, drug and food interactions, the effects of intercurrent illness and dose variability. The report in this issue of Heart by Jones and colleagues ${ }^{9}$ examines the relation of warfarin control and outcomes in more detail, revealing that patients in their study spent approximately $30 \%$ of the time outside target international normalised
Heart 2005;91:423-424. doi: 10.1136/hrt.2004.047902

ratio (INR) values. Although a registry based study, and as such unable to control for confounding factors such as illness or medication changes, suboptimal control was clearly linked with an increased risk of ischaemic stroke or bleeding.

Near patient testing (NPT) with computerised support can improve on this level of poor control, with one study showing only $14 \%$ of patients outside of target INR range. ${ }^{10}$ Studies of self managed patients have recorded just $26 \%$ of results outside of target range. ${ }^{11}$ Although such studies have involved smaller numbers of patients compared to Jones's study, they do demonstrate an alternative mode of service delivery involving primary care that has the added benefit of improved patient satisfaction. ${ }^{10-12}$ In the current financial climate, there would need to be significant incentives for general practitioners to develop and deliver such a warfarin based anticoagulation service.

\section{ORAL DIRECT THROMBIN INHIBITORS}

Does the new oral direct thrombin inhibitor ximelagatran represent a suitable alternative to warfarin for the individual patient? Data from the SPORTIF III and V studies shows promising results in stroke risk reduction in $\mathrm{AF}$, with comparable effects to warfarin in direct trials in prevention of stroke and systemic embolic events. ${ }^{13}{ }^{14}$ Ximelagatran presents an attractive proposition with no significant food or drug interactions, fixed dosing, and no need to monitor its anticoagulant effects as the target of appropriate anticoagulation is taken as read. There is, however, still a need for blood tests and monitoring as $6 \%$ of patients developed abnormal liver function tests in the SPORTIF trials.

Ximelagatran compared favourably with warfarin in terms of major non-stroke related haemorrhage risk (1.3\%/annum with ximelagatran $v 1.8 \%$ /annum with warfarin) in the SPORTIF III trial and has been heralded by some as the anticoagulant of choice for older people with AF. ${ }^{15}$ However, this may prove to be an optimistic prediction as parity in bleeding events was based on patients taking ximelagatran at an appropriate, non-monitored level of anticoagulation compared with $44 \%$ of warfarin subjects out of range (INR > 3.0). ${ }^{13}$ The advent of NPT schemes and tighter warfarin control may negate much of the considered benefit of ximelagatran if effective NPT control can reduce bleeding rates with warfarin.

Abbreviations: AF, atrial fibrillation; INR, international normalised ratio; NPT, near patient testing 
Although rates of minor bleeding were less with ximelagatran, the parity in major bleeding episodes suggests that uptake of ximelagatran is unlikely to be significantly greater than existing rates of warfarin prescribing as physicians and individual patients are still faced with comparable rates of potentially lethal bleeding, a factor shown to be key in decisions whether to choose anticoagulation. ${ }^{78}$ For older patients, a group often excluded from anticoagulant therapy, this comparable risk of major bleeding may not alter current practices of avoiding anticoagulation because of concerns regarding adverse events. ${ }^{16}$

\section{INDIVIDUALISING PATIENT RISK AND DECISION MAKING IN AF}

Given the individual and economic burden of AF related stroke disease, how can anticoagulant prescribing be improved? While systematised approaches to prescribing may raise awareness of the need for anticoagulation, this strategy alone is unlikely to be successful in increasing numbers of eligible patients receiving anticoagulation unless supported by a more individualised approach to treatment choice. The use of a more detailed and individualised stroke risk estimate based on risk factors and an estimate of intracerebral bleeding risk may help an individual reach a more informed decision about whether or not to choose warfarin. $^{48}$

However, there are some emerging concerns. Data about the increased risks of anticoagulation in patients with cerebral small vessel disease is likely to complicate further any risk versus benefit calculation. For many patients with $\mathrm{AF}$ and increased risk of embolic stroke, their concurrent vascular co-morbidities-namely hypertension, diabetes mellitus, and older age-are also risks for small vessel disease and the associated increased rates of intracerebral bleeding when anticoagulated or given antiplatelet agents. ${ }^{18} 18$ The routine use of magnetic resonance imaging in AF patients to rule out the presence of microbleeds that can mark out an individual at an increased risk of intracerebral bleeding may be one way of improving patient choice and use of an anticoagulant agent.

Much of this may seem rather theoretical and rather impractical to the busy clinician. However, it is important as just as clinicians have a responsibility to obtain informed consent for interventional procedures, the potential risks associated with the use of warfarin or an alternative agent means that physicians too have a legal responsibility to inform patients of significant risks so that a patient has the information available to determine what treatment should be accepted or rejected. ${ }^{19}$

Achieving successful management of AF and stroke risk reduction is unlikely to be achieved solely through wholesale adoption of new direct thrombin inhibitors over warfarin, but through careful selection of patients and discussion of individualised risk and benefit information. Using decision and risk models to examine the relative merits of treatment, developing NPT and computerised dosing support if newer agents prove too expensive, and most importantly understanding the individual patient's choices for treatment should be key targets for all clinicians to combat the growing AF epidemic and improve the wider and appropriate use of anticoagulants.

\section{Authors' affiliations}

R Fuller, Medical Department for the Elderly, The General Infirmary at Leeds, Leeds, UK

N J Dudley, Elderly Services, St James's University Hospital, Leeds, UK

\section{REFERENCES}

1 Steinberg JS. Atrial fibrillation: an emerging epidemic? Heart 2004;90:239-40.

2 Stewart S, Murphy N, Walker A, et al. Cost of an emerging epidemic: an economic analysis of atrial fibrillation in the UK. Heart 2004;90:286-92.

3 Wolf PA, Abbott RD, Kannel WB. Atrial fibrillation as an independent risk factor for stroke: the Framingham study. Stroke 1991;22:983-8.

4 Gage BF, Waterman AD, Shannon W, et al. Validation of clinical classification schemes for predicting stroke. JAMA 2001;285:2864-70.

5 Hart RG. Warfarin in atrial fibrillation: underused in the elderly, often inappropriately used in the young. Heart 1999;82:539-40.

6 Sudlow M. Thomson R, Thwaites B, et al. Prevalence of atrial fibrillation and eligibility for anticoagulants in the community. Lancet 1998;352:1167-71.

7 Monette J, Gurwitz, Rochon PA, et al. Physician attitudes concerning warfarin for stroke in prevention in atrial fibrillation: results of a survey of long-term care practitioners. J Am Geriatr Soc 1999;45:1060-5.

8 Fuller R, Dudley NJ, Blacktop J. Avoidance hierarchies and preferences for anticoagulation-semi qualitative analysis of older patients' views about stroke prevention and the use of warfarin. Age Ageing 2004;33:608-11.

9 Jones M, McEwan P, Morgan CL, et al. Evaluation of the pattern of treatment, level of anticoagulation control, and outcome of treatment with warfarin in patients with non-valvar atrial fibrillation: a record linkage study in a large British population. Heart 2005;91:472-7

10 FitzMaurice DA, Hobbs FDR, Murray ET, et al. Evaluation of computerised decision support for oral anticoagulation management based in primary care. Br J Gen Pract 1996;46:533-5.

11 FitzMaurice DA, Murray ET, Gee K, et al. A primary care based study of patient self-management of oral anticoagulation. $\mathrm{Br} J \mathrm{Haem}$ 2000;108(S1): 130

12 Cromheecke ME, Levi M, Colly LP, et al. Oral anticoagulation self management and management by a specialist anticoagulation clinic: a randomised cross-over comparison. Lancet 2000;356:97-102.

13 Executive Steering Committee, on behalf of the SPORTIF III Investigators. Stroke prevention with the oral direct thrombin inhibitor ximelagatran compared with warfarin in patients with non-valvular atrial fibrillation (SPORTIF III): randomized controlled trial. Lancet 2003;362:1691-8.

14 Anon. Cardiovascular News. The SPORTIF V results. Circulation 2003; 108:e9051

15 Hankey GJ, Klijn CJM, Eikelboom JW. Ximelagatran or warfarin for stroke prevention in patients with atrial fibrillation? Stroke 2004;35:389-91.

16 Brophy MT, Snyder KE, Gaehde S, et al. Anticoagulant use for atrial fibrillation in the elderly. J Am Geriatr Soc 2004;52:1151-6.

17 Diener HC, Bogousslavsky J, Brass LM, et al. Aspirin and clopidogrel compared with clopidogrel alone after recent ischaemic stroke or transient ischaemic attack in high-risk patients (MATCH): randomised, double blind, placebo-controlled trial. Lancet 2004;364:331-7.

18 Gorter JW. Major bleeding during anticoagulation after cerebral ischaemia: patterns and risk factors. Stroke prevention in reversible ischaemia trial (SPIRIT). European atrial fibrillation trial (EAFT) study groups. Neurology 1999;53:1319-27.

19 Pearce v United Bristol Healthcare NHS Trust, [1999] PIQR P53 at p59. 